\title{
ESTUDO DA FRAGILIDADE OSMÓTICA E FOSFOLÍPIDEOS TOTAIS EM CONCENTRADOS DE HEMÁCIAS COM NANOEMULSÕES DE VITAMINA E
}

\author{
Tiago H. S. Souza ${ }^{1, *}$, Carlos A. L. Silva ${ }^{1}$, Paulo E. Cabral Filho ${ }^{1}$, Goreti Pereira ${ }^{2}$, Vera C. O. Carvalho ${ }^{3}$, \\ Vera L. M. Lima ${ }^{3}$, Beate S. Santos ${ }^{4}$, Adriana Fontes ${ }^{1}$
}

${ }^{1}$ Laboratório de Biofísica Química, Departamento de Biofísica e Radiobiologia - UFPE; ${ }^{2}$ Departamento de Química Fundamental - UFPE; ${ }^{3}$ Departamento de Bioquímica - UFPE; ${ }^{4}$ Departamento de Ciências Farmacêuticas - UFPE.

*thiago.phss@hotmail.com

\section{INTRODUÇÃO}

Nos bancos de sangue é comum o armazenamento de bolsas de concentrados de hemácias $(\mathrm{CHs})$, entretanto durante esse período ocorrem alterações celulares, denominadas de lesões de estocagem. Essas lesões são caracterizadas por desde alterações bioquímicas e biofísicas celulares até alterações morfológicas, ocasionando, por exemplo, mudanças no potencial zeta e na elasticidade eritrocitária, as quais podem levar à diminuição do rendimento transfusional (SILVA et al., 2012). Dentre as lesões de estocagem, aquelas que estão diretamente relacionadas à gradual oxidação das proteínas ou lipídios de membrana, tem potencial para serem evitadas através do uso de substâncias antioxidantes (RACEK et al. 1997). Sendo assim, o uso dessas substâncias em CHs pode ajudar a aumentar o rendimento transfusional por diminuir as lesões de estoque.

A vitamina $E$ é um antioxidante lipossolúvel, com comprovada ação em lipídios por diminuir a peroxidação dos ácidos graxos, como aqueles presentes na membrana celular (RACEK et al. 1997). Alguns estudos já demonstraram que a vitamina E utilizada como suplemento pode melhorar sintomas clínicos de indivíduos com anemias hereditárias ou aqueles que apresentam aumento do estresse oxidativo, como os portadores da anemia falciforme (CHAN et al., 1999). Além disso, já é reportado que a concentração de vitamina E presente na membrana protege as hemácias contra lise (MAY, 1998). Recentemente também foi reportado que nanoemulsões de vitamina $E$ podem diminuir a produção de espécie reativas de oxigênio em CHs (SILVA et al., 2017).

Sendo assim, este trabalho teve como objetivo avaliar parâmetros biofísico-químicos após adição de nanoemulsão de vitamina $\mathrm{E}$, como possível agente antioxidante em $\mathrm{CHs}$ de CPD/SAG-M. Foram analisados os seguintes parâmetros: a fragilidade osmótica, a composição de fosfolipídeos totais e a dosagem de colesterol da membrana eritrocitária, no primeiro e após 42 dias de estocagem.

\section{MATERIAIS E MÉTODOS}

\section{Preparação das Formulações}

Devido a sua natureza hidrofóbica, a vitamina E (Sigma Aldrich) foi dispersa em meio aquoso em forma de nanoemulsão, como descrito previamente em Silva et al. 2017. Em forma de emulsão a interac ao da vitamina $\mathrm{E}$ com as hemácias dos $\mathrm{CHs}$, torna-se possí vel. A preparação dessas nanoemulsões envolveu a combinação de 3 componentes: SAG-M ( $50 \mathrm{~mL}$ - Fresenius Kabi), óleo (160 mg de vitamina E) e tensoativos ( $265 \mathrm{mg}$ de Tween 20 e $265 \mathrm{mg}$ de Tween 80 - Sigma Aldrich). A formulação foi preparada de forma a atingir uma concentração de $0,2 \mathrm{mg} / \mathrm{mL}$ no $\mathrm{CH}$. As nanoemulsões apresentaram um tamanho de aproximadamente $20 \mathrm{~nm}$, avaliado por espalhamento dinâmico de luz (Zetasizer Nano ZS 90, Malvern Instruments).

\section{Amostra de Hemácias}

As hemácias para análise foram obtidas a partir de segmentos de $\mathrm{CHs}$ de CPD/SAG-M estocadas no HEMOPE (CAEE 41109115.6.3001.5195). Cada bolsa foi dividida em duas unidades. Uma das unidades recebeu a formulação da vitamina $E$, conforme descrito na seção anterior (teste). A outra unidade recebeu a mesma quantidade do solvente (sem vitamina) e foi considerada como controle. As formulações foram adicionadas as bolsas de sangue de forma asséptica e, em seguida, os $\mathrm{CHs}$ foram armazenados a $4{ }^{\circ} \mathrm{C}$. Foram avaliados cinco $\mathrm{CHs}$. Após teste de normalidade por Shapiro-Wilk, foi identificado que as amostras não seguiam distribuição normal, assim as diferenças e similaridades estatísticas apresentadas entre grupos controle e teste foram avaliadas estatisticamente pelo teste de Wilcoxon, com nível de significância de 0,05.

\section{Fragilidade Osmótica}

A fragilidade osmótica das hemácias, estocadas a curto (primeiro dia) e longo prazo (42 dias), das amostras tratadas ou não com vitamina $\mathrm{E}$ foi avaliada tal como descrito por Moore e co-autores (MOORE, 1968), com modificações. Diluiu-se as células a serem testadas de 1:100 com soluc ao salina. A seguir, adicionou-se 0,3 $\mathrm{mL}$ da soluc ao acima em $4,5 \mathrm{~mL}$ de soluções salinas (nas concentrações de 0,9 a $0,3 \%$, com intervalos de 0,1 ) misturando rapidamente e leu-se a densidade óptica a $675 \mathrm{~nm}$ após 60 segundos, para cada tubo. A partir da densidade óptica, encontrouse o percentual de hemólise para as diversas concentrações.

Composição de Lipídeos Totais da Membrana de Hemácias Os lipídeos foram extraídos a partir da membrana de hemácias, estocadas a curto e longo prazo, como descrito por Folch e colaboradores (1957). A extração lipídica foi realizada adicionandose vagarosamente $0,5 \mathrm{~mL}$ de suspensão de hemácias a um tubo contendo $7,0 \mathrm{~mL}$ de metanol sob agitação constante, logo após se acrescentou $14,0 \mathrm{~mL}$ de clorofórmio. Filtrou-se a solução final e completou-se com uma solução de clorofórmio/metanol (2:1 v/v) para um volume final de $40 \mathrm{~mL}$. Em seguida, foram adicionados 8,0 $\mathrm{mL}$ de $\mathrm{KCl}$.

A partir dos extratos lipídicos foram realizadas as dosagens quí micas dos fosfolipídios totais (FLT), (método de Bartlett, 1959) e 
de colesterol pelo kit enzimático (Labtest Sistemas Diagnósticos Ltda) (BARTLET, 1959).

O objetivo principal desse estudo biofísico-químico com a vitamina E foi verificar se a redução de espécies reativas reportada por Silva et al. 2017 poderia ter correlação com a composição lipídica da membrana eritrocitária e a resistência a variações osmóticas. Para estes estudos, escolheu-se realizar análises nos extremos do perí odo de armazenamento a fim de detectar variações mais significativas.

\section{RESULTADOS E DISCUSSÃO}

\section{Fragilidade Osmótica}

Os resultados da fragilidade osmótica para $\mathrm{CHs}$ contendo ou não a vitamina $\mathrm{E}$, estão apresentados na Figura 1. Os resultados demonstram que a percentagem de hemólise de todas as amostras no final da estocagem foi significativamente maior quando comparada ao início $(p=0,03)$. Foi constatado, ainda, que quando as hemácias estocadas foram incubadas com as nanoemulsões com vitamina $E$, não houve diferença em relação ao grupo controle $(p=$ $0,5)$.

Estes resultados são corroborados pela literatura que constata que as hemácias, durante o período de estocagem, perdem a resistê ncia à hemólise em meios hipotônicos (RAVAL et al., 2013; ALMIZRAQ et al., 2013). Vários estudos vêm sendo realizados para estabelecer uma correlação entre o aumento da fragilidade osmó tica e o estresse oxidativo (SROUR, et al., 2000; RINALDUCCI et al., 2011; D’ALESSANDRO et al., 2012; GRAZZINI e VAGLIO, 2012). No entanto, o estresse oxidativo relacionado às proteínas, e não aos lipídeos, tem sido apontado como o fator mais crítico para o comportamento reológico, incluindo a fragilidade osmótica e a elasticidade (SROUR, et al., 2000; KRIEBARDIS et al., 2007; HALE et al., 2011, SILVA et al. 2017). Dessa forma, sugere-se que a vitamina $E$ não modificou a resistência à hemólise, pois atua principalmente prevenindo a lipoperoxidação.

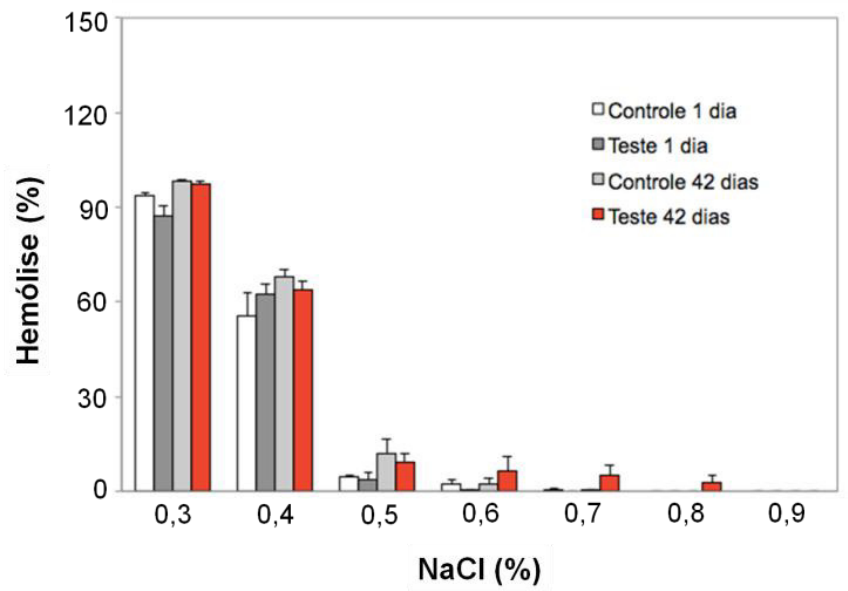

Figura 1. Fragilidade osmótica eritrocitária em função de concentrações de $\mathrm{NaCl}$, com e sem a emulsão de vitamina $E$.

\section{Composição de Lipídeos Totais de Membrana de Hemácias}

Os valores de colesterol e fosfolipídeos obtidos para as membranas das hemácias dos CHs estão apresentados nas Figuras 2 e 3. Os nossos resultados indicaram que a dosagem de fosfolipídeos totais reduziu, cerca de $15 \%$, no último dia em relação ao primeiro em ambas as amostras $(p=0,04)$ com ou sem vitamina $E$. No entanto, não houve diferença entre as amostras controles e testes $(p=0,2)$.

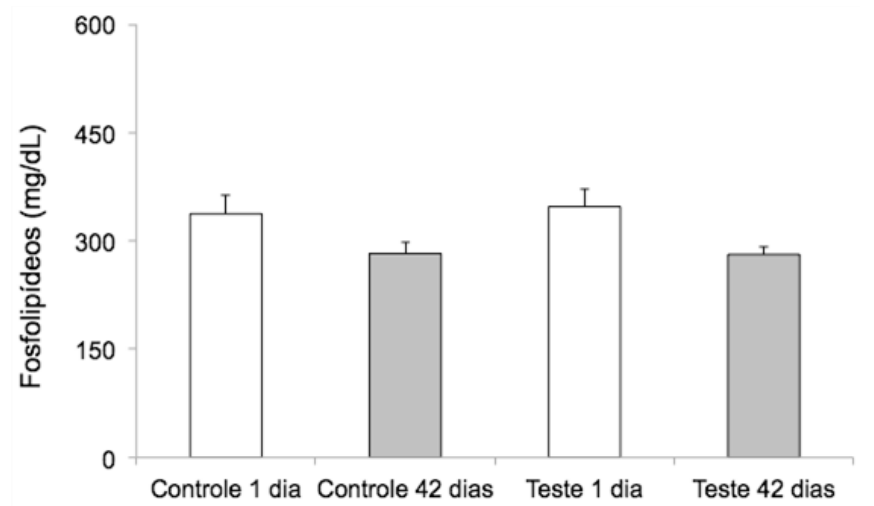

Figura 2. Médias das concentrações de fosfolipídeos totais de membranas de hemácias estocadas a curto e longo prazo, com e sem vitamina E.

A dosagem de colesterol (Figura 3) demonstrou uma redução em torno de $8 \%$ do primeiro dia para o último dia de estocagem das amostras $(p=0,04)$. Entretanto, não houve diferenças significativas entre a concentração de colesterol de membranas de hemácias provindos de $\mathrm{CH}$ s com e sem nanoemulsão de vitamina $\mathrm{E}$ para curto e longo prazo $(p=0,2)$.

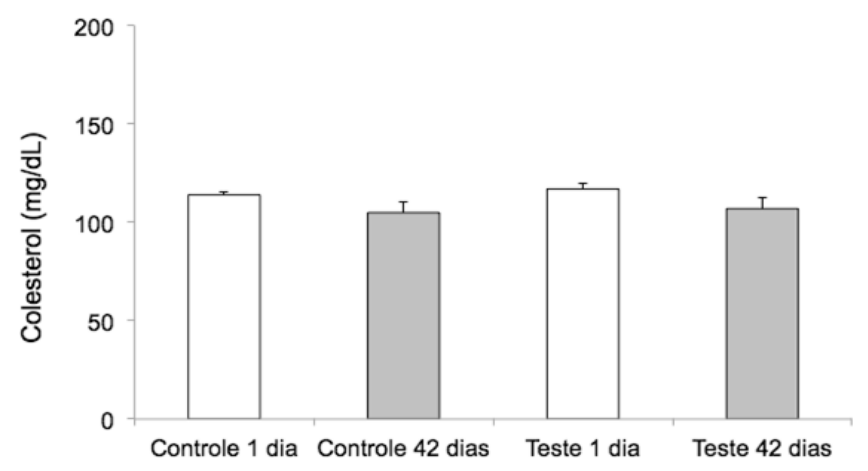

Figura 3. Médias das dosagens de colesterol de membranas de hemácias estocadas a curto e longo prazo, com e sem vitamina $\mathrm{E}$.

Os valores de fosfolipídeos e colesterol, encontrados neste estudo, bem como a sua redução em função do armazenamento, estão de acordo com dados relatados na literatura, embora tenham sido realizados com bolsas estocadas em outras soluções aditivas e/ou lecorreduzidas (WAGNER et al., 1987; GREENWALT et al., 1990; DRAPER et al., 2002; ALMIZRAQ, et al., 2013).

A perda lipídica ao longo do armazenamento está relacionada à formação de microvesículas que se desprendem da membrana eritrocitária (WILLEKENS et al., 2008). Adicionalmente, Wagner e co-autores relataram que a oxidação da proteína espectrina está correlacionada com essa vesiculação (WAGNER et al., 1987). Assim, mais uma vez reforça-se a hipótese de que a utilização de antioxidantes que tenham ação em proteínas combinados à vitamina $E$, podem ser mais eficientes nas lesões de estoque do que os que atuam apenas em lipídeos, como também sugerido por Silva et al., 2017.

\section{CONCLUSÕES}

As análises biofísico-químicas indicaram que as hemácias de $\mathrm{CHs}$ após 42 dias de estocagem perdem a resistência a perturbações osmóticas, tendem a hemolisar e perdem lipídeos e colesterol de membrana durante a estocagem em bolsas de CPD/SAG-M. A nanoemulsão de vitamina $E$ não interferiu nessas alterações, provavelmente pelo fato desta substância ser um antioxidante lipí 
dico e, tais mudanças estarem relacionadas com as proteínas membranares, como também já sugerido pela literatura. Assim mais estudos com antioxidantes proteicos (combinados ou não com vitamina E) também merecem atenção, visando uma melhor preservação das propriedades eritrocitárias durante armazenamento.

\section{REFERÊNCIAS}

ALMIZRAQ, R. et al. Storage of red blood cells affects membrane composition, microvesiculation, and in vitro quality. Transfusion, v. 53, n. 10 , p. $2258-2267,2013$

BARTLETT, G. R. Phosphorus assay in column chromatography, J. Biol. Chem, v. 234, p. 466-468, 1959.

CHAN, A C.; CHOW, C. K.; CHIU, D. Interaction of antioxidants and their implication in genetic anemia. Proceedings of the Society for Experimental Biology and Medicine. Society for Experimental Biology and Medicine (New York, N.Y.), v. 222, n. 3, p. 274-282, 1999.

D'ALESSANDRO, A. et al. Time-course investigation of SAGM-stored leukocyte-filtered red blood cell concentrates: From metabolism to proteomics. Haematologica, v. 97, n. 1, p. 107-115, 2012.

DRAPER, C. J.; GREENWALT, T. J.; DUMASWALA, U. J. Biochemical and structural changes in RBCs stored with different plasticizers: the role of hexanol. Transfusion, v. 42, n. 7, p. 830-835, 2002.

FOLCH, J.; LESS, M.; STANLEY, G. H. S. A simple method for the isolation and purification of total lipids animal tissues. J. Biol. Chem., v. 226, p. 497-510, 1957.

GRAZZINI, G.; VAGLIO, S. Red blood cell storage lesion and adverse clinical outcomes: Post hoc ergo propter hoc? Blood Transfusion, v. 10, n. SUPPL. 2, p. 10-12, 2012.

GREENWALT, T. J.; BRYAN, D. J.; DUMASWALA, U. J. Erythrocyte Membrane Vesiculation and Changes in Membrane Composition during Storage in Citrate-Phosphate-Dextrose-Adenine-1. Vox Sanguinis, v. 47, n. 4, p. 261-270, 1984.

HALE, J. P.; WINLOVE, C. P.; PETROV, P. G. Effect of Hydroperoxides on Red Blood Cell Membrane Mechanical Properties. Biophysical Journal, v. 101, 1921-1929, 2011.

KRIEBARDIS, A. G. et al. Progressive oxidation of cytoskeletal proteins and accumulation of denatured hemoglobin in stored red cells. Journal of Cellular and Molecular Medicine, v. 11, n. 1, p. 148-155, 2007.

MAY, J. M. Ascorbate function and metabolism in the human erythrocyte. Frontiers in Bioscience: a Journal and Virtual Library, v. 3, p. d1-10, 1998.

MOORE, T. J. Glycerol permeability of human fetal and adult erythrocytes and of a model membrane, Journal of Lipid Research, v.9, p. 642-646, 1968.

RACEK, J. et al. Influence of antioxidants on the quality of stored blood. Vox Sanguinis, V. 72, p. 16-19, 1997.

RAVAL, J. S. et al. Ascorbic acid improves membrane fragility and decreases haemolysis during red blood cell storage. Transfusion Medicine, v. 23, n. 2, p. 87-93, 2013.

RINALDUCCI, S. et al. Peroxiredoxin-2 as a candidate biomarker to test oxidative stress levels of stored red blood cells under blood bank conditions. Transfusion, v. 51, n. 7, p. 1439-1449, 2011.

SILVA, C. A. L. et al. Vitamin E nanoemulsion activity on stored red blood cells. Transfusion Medicine, v. 27, 213-217, 2017.

SILVA, D. C. N. et al. Optical Tweezers as a New Biomedical Tool to Measure Zeta Potential of Stored Red Blood Cells. Plos One, v. 7, p. e31778, 2012.
SROUR, M. A. et al. Exposure of human erythrocytes to oxygen radicals causes loss of deformability, increased osmotic fragility, lipid peroxidation and protein degradation. Clinical Hemorheology and Microcirculation, v. 23, n. 1, p. 13-21, 2000.

WAGNER, G. M. et al. Spectrin oxidation correlates with membrane vesiculation in stored RBCs. Blood, v. 69, n. 6, p. 1777-1781, 1987.

WILLEKENS, F. L. A. et al. Erythrocyte vesiculation: a selfprotective mechanism? British Journal of Haematology, v. 141, n. 4, p. 549-556, 2008. 